\title{
多晶硅太阳能电池片的回收再利用研究
}

\author{
李佳艳 ${ }^{1,2}$, 蔡 敏 ${ }^{1,2}$, 武晓玮 ${ }^{1,2}$, 谭 毅 ${ }^{1,2}$
}

(1. 大连理工大学 材料科学与工程学院, 大连 $116024 ; 2$. 辽宁省太阳能光伏重点实验室, 大连 116024)

摘 要: 从废弃的太阳能电池片中回收多晶硅原材料对于环境保护和材料的循环再利用具有重要意义。本文研究了 用化学溶解和超声清洗回收电池片的最佳条件。分别对实验样品进行 EDS、SEM、XPS 分析, 得出结论: 电池片与质 量分数为 $10 \%$ 的氢氧化钠溶液反应 $18 \mathrm{~min}$ 完全去除铝电极, 且硅晶片的损失率较小; 将完全去除铝电极的电池片 在 $40 \mathrm{kHz}$ 超声清洗 $20 \mathrm{~min}$ 后银电极完全剥落; 电池片与 $40 \%$ 氢氟酸溶液反应 $10 \mathrm{~min}$ 可以去除氮化硅膜。本研究 对质量为 $8.9068 \mathrm{~g}$ 的单片电池片进行了定量分析, 除去的铝电极质量为 $1.1102 \mathrm{~g}$, 回收得到了 $0.0766 \mathrm{~g}$ 的银电极和 $7.7169 \mathrm{~g}$ 的硅晶片。

关 键 词: 多晶硅; 太阳能电池片; 回收

中图分类号: TQ174 文献标识码: A

\section{Recycling Polycrystalline Silicon Solar Cells}

\author{
LI Jia-Yan ${ }^{1,2}$, CAI Min ${ }^{1,2}$, WU Xiao-Wei ${ }^{1,2}$, TAN Yi ${ }^{1,2}$
}

(1. School of Materials Science and Engineering, Dalian University of Technology, Dalian 116024, China; 2. Key Laboratory for Solar Energy Photovoltaic System of Liaoning Province, Dalian 116024, China)

\begin{abstract}
Recovering Si material from the degraded solar cells is significant for environmental protection and material recycling. In this tudy, the optimal conditions for recycling degraded solar cells by chemical etching and ultrasonic cleaning were investigated. The samples were tested by EDS, SEM and XPS, The results showed that Al electrodes were completely removed from cells by reaction with $10 \mathrm{wt} \% \mathrm{NaOH}$ solution for $18 \mathrm{~min}$, with less silicon corrosion lost. After that, Ag electrodes were completely exfoliated from the cells by ultrasonic cleaning (40 kHz) for $20 \mathrm{~min}$. $\mathrm{Si}_{3} \mathrm{~N}_{4}$ film was thoroughly eliminated after the cells were etched with $40 \mathrm{wt} \%$ HF solution for 10 min, which was proved to be the optimal reaction time. A quantitative experiment was performed in this study with $8.9068 \mathrm{~g}$ cells. The results show that the recycling mass of $\mathrm{Al}$ electrodes, $\mathrm{Ag}$ electrodes and Si wafers are $1.1102 \mathrm{~g}, 0.0766 \mathrm{~g}$ and $7.7169 \mathrm{~g}$, respectively.
\end{abstract}

Key words: polycrystalline silicon; solar cells; recycle

当今世界正面临着空前的环境和能源危机，煤 炭、原油、天然气等传统能源将在未来 40 60 年枯 竭。这些化石能源的缺乏, 严重制约着世界经济和 社会的发展。与此同时, 化石燃料燃烧产生的大量 $\mathrm{CO}_{2}$ 加剧了全球温室效应。世界各国开始重视开发 安全、清洁、高效的新兴能源。太阳能作为一种新
兴的可再生能源具有如下优势 ${ }^{[1]}$ : (1) 储量丰富; (2) 长久性; (3) 普遍性; (4) 洁净安全; (5)经济性。因此 显现出广阔的发展前景。

在众多太阳能电池中, 晶体硅太阳能电池一直 占据光伏市场的主导地位。晶硅太阳能电池光伏系 统主要包含硅、铝、银、铜、玻璃和塑料等材料。

收稿日期: 2017-11-16; 收到修改稿日期：2018-01-18

基金项目: 国家自然科学基金(51574057) National Natural Science Foundation of China (51574057)

作者简介: 李佳艳(1980-), 女, 副教授. E-mail: lijiayan@dlut.edu.cn

通讯作者: 谭 毅, 教授. E-mail: tanyi@dlut.edu.cn 
其中, 电池的主要部分一一多晶硅具有很高的回收 价值, 其余的材料如铝背板、银栅线、镀锡铜线和 玻璃等的回收价值 ${ }^{[2-5]}$ 也不可小觑。

此外, 随着太阳能电池固体废弃物的大幅增长, 也使得研发太阳能电池片的低成本回收技术势在必 行。由于整个光伏系统组件老化等原因, 预计到 2020 年, 将会有大批的太阳能电池面临退役。届时, 太阳能电池的累计废弃量会给环境造成重压 ${ }^{[6-7]}$ 。与 此同时, 太阳能电池原材料的需求也随之增加。如 果能将废弃的太阳能电池片回收利用, 则既可以解 决环境问题, 又可以降低产业成本。有研究表明 ${ }^{[8-9]}$, 将回收之后的硅晶片经过熔铸形成高纯硅, 比起从 石英砂中提炼硅, 其成本要低得多。

目前, 国外比较先进的回收太阳能电池片的技 术有以下两种: (1)比利时 BP Solar 公司 ${ }^{[10]}$ 曾经将 36 个电池片组成的太阳能电池组件放入硝酸中, 在 $60^{\circ} \mathrm{C}$ 下反应 $25 \mathrm{~h}$, 将电池片组件进行分离。同时, 电池片 的正电极银和负电极铝也完全去除, 成功回收硅晶 片。(2)德国的 Deutsche Solar AG 研发了一种晶体硅 光伏组件示范技术, 是至今比较成熟的回收方法 ${ }^{[11]}$ 。

我国对太阳能电池回收的研究集中在包括各个 组件的整体回收, 但尚未有成熟的技术手段来解决 组件中单个组分的回收利用问题。且国外对太阳能 电池片的回收技术也存在一定问题, 比如反应时间 长、能耗大等 ${ }^{[12]}$ 。

本研究为了实现多晶硅太阳能电池片的高效回 收再利用, 采用化学溶解及超声清洗法去除太阳能 电池片背面铝电极、正面银电极以及氮化硅减反射 膜, 得到了纯净的硅晶片, 确定了本研究的最佳实 验条件。

\section{1 实验方法}

\section{1 铝背电极的去除}

分别配置 $50 \mathrm{~mL}$ 质量分数为 $5 \%$ 、 $10 \%$ 和 $15 \%$ 的氢氧化钠 $(A R$, 天津市大茂化学试剂厂)溶液, 置 于 $100 \mathrm{~mL}$ 的烧杯中, 称取约 $0.2 \mathrm{~g}$ 太阳能电池片分 别浸入氢氧化钠溶液中在室温下反应, 设置六组实 验, 反应时间分别为 $9 、 12 、 15 、 18 、 21$ 和 $24 \mathrm{~min}$ 。 将不同反应条件下获得的电池片用去离子水清洗, 烘干。

\section{2 银正电极的去除}

取已去除铝电极的电池片, 分别进行氨水 $(25 \%$ 28\%, AR, 天津市大茂化学试剂厂)、双氧水 (30\%, AR, 天津市科密欧化学试剂有限公司)混合溶 液(体积比为 $1: 1$ ) 溶解 $1 \mathrm{~h}$ 、超声清洗(频率为 $40 \mathrm{kHz}$ )
$20 \mathrm{~min}$, 去除银电极。将不同反应条件下获得的电 池片用去离子水清洗, 烘干 ${ }^{[13-16]}$ 。

\section{3 氮化硅膜的去除}

取已去除铝电极和银电极的电池片, 与氢氟酸 溶液 $(40 \%, \mathrm{AR}$, 天津市天力化学试剂有限公司)直 接反应, 反应时间为 $10 \mathrm{~min}$ 。将反应之后的电池片 用去离子水清洗，烘干。

\section{4 定量分析}

取一片完整的多晶硅太阳能电池片, 用去离子 水清洗, 烘干, 用本次研究所得最佳实验条件去除 铝电极, 清洗烘干; 用本次研究所得最佳实验条件 去除氮化硅膜和银电极, 将剥落的银电极以及回收 到的硅晶片分别清洗烘干。

\section{5 表征方法}

通过 TM3030Plus 型扫描电子显微镜获得电池 片微观形貌; 通过 SUPARR 55 型场发射扫描电镜 获得 $\mathrm{X}$ 射线能谱分析数据; 通过 ESCALAB 250Xi 型 X 射线光电子能谱仪获得 XPS 能谱扫描结果, 并 用软件 XPS peakfit $4.1^{[17]}$ 进行拟合获得最终结果。

\section{2 结果与讨论}

采用氢氧化钠溶液去除背面铝电极, 反应式为:

$$
2 \mathrm{Al}+2 \mathrm{OH}^{-}+6 \mathrm{H}_{2} \mathrm{O} \rightarrow 2\left[\mathrm{Al}(\mathrm{OH})_{4}\right]^{-}+3 \mathrm{H}_{2} \uparrow
$$

由于硅和碱之间会发生反应, 当完全去除铝电 极后, 随着反应时间的延长, 氢氧化钠会腐蚀硅晶 片, 反应式为:

$$
\mathrm{Si}+2 \mathrm{OH}^{-}+\mathrm{H}_{2} \mathrm{O} \rightarrow \mathrm{SiO}_{3}^{2-}+2 \mathrm{H}_{2} \uparrow
$$

为了避免硅晶片被氢氧化钠腐蚀造成浪费, 需 要对反应时间进行控制。

采用氨水双氧水混合溶液去除银电极, 双氧水 可以将银氧化成银离子, 之后氧化银与氨水发生络 合反应，形成银氨溶液，反应式如下:

$$
\mathrm{H}_{2} \mathrm{O}_{2}+2 \mathrm{Ag} \rightarrow \mathrm{Ag}_{2} \mathrm{O}+\mathrm{H}_{2} \mathrm{O}
$$

$$
\mathrm{Ag}_{2} \mathrm{O}+4 \mathrm{NH}_{3} \cdot \mathrm{H}_{2} \mathrm{O} \rightarrow 2\left[\mathrm{Ag}\left(\mathrm{NH}_{3}\right)_{2}\right]^{+}+2 \mathrm{OH}^{-}+4 \mathrm{H}_{2} \mathrm{O} \text { (4) }
$$

采用氢氟酸溶液去除氮化硅减反射膜, 反应式 如下:

$$
12 \mathrm{HF}+\mathrm{Si}_{3} \mathrm{~N}_{4} \rightarrow 3 \mathrm{SiF}_{4} \uparrow+4 \mathrm{NH}_{3} \uparrow
$$

$\mathrm{SiF}_{4}$ 和 $\mathrm{NH}_{3}$ 常温下均为气体, 反应之后逸出, 得到 纯净的硅片。

\section{1 铝背电极的去除}

图 1 为原电池片铝背电极的 SEM 照片。去除铝 电极结果如图 2 所示, 电池片分别与 $5 \mathrm{wt} \% 、 10 \mathrm{wt} \%$ 、 $15 \mathrm{wt} \%$ 的氢氧化钠溶液反应 $24 、 18$ 和 $15 \mathrm{~min}$, 可以 完全去除铝电极。 


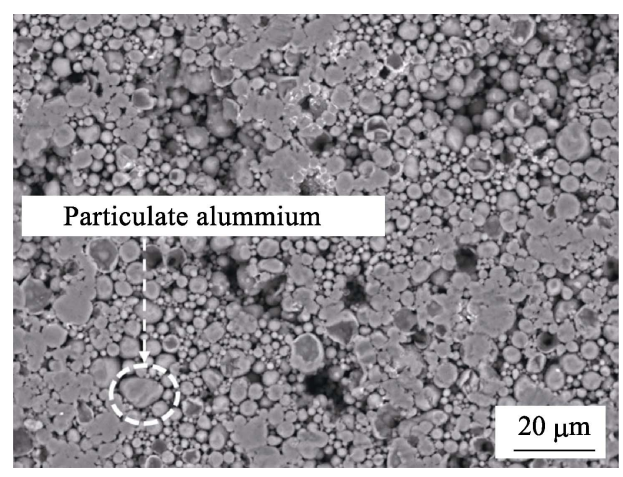

图 1 原电池片铝背电极的 SEM 照片

Fig. 1 SEM image of rear face of the multicrystalline cell before etched

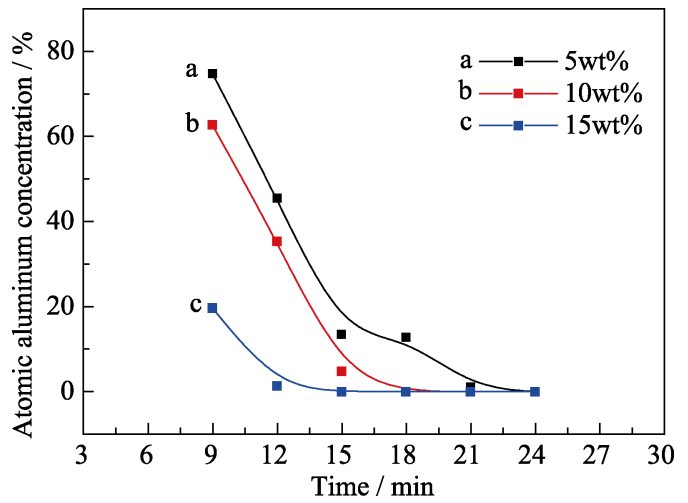

图 2 电池片分别与 $5 \mathrm{wt} \% 、 10 \mathrm{wt} \%$ 和 $15 \mathrm{wt} \%$ 氢氧化钠溶液 反应不同时间后的表面铝原子含量分析

Fig. 2 EDS analysis of rear faces of multicrystalline cells after etching in $5 \%, 10 \%$ and $15 \% \mathrm{NaOH}$ solution with different reaction time

图 3 为电池片与 $5 \mathrm{wt} \%$ 氢氧化钠溶液反应后的 SEM 照片。如图 3(a) (e)所示, 随着反应时间延长, 铝电极的厚度逐渐减小。由图 3(f) 可以看出, 在反应 $24 \mathrm{~min}$ 后铝电极完全去除, 与能谱扫描结果一致,
并且电池片表面可见硅晶片与氢氧化钠反应后留下 的细微凹槽。

图 4 为电池片与 $10 \mathrm{wt} \%$ 氢氧化钠溶液反应不同 时间后的 SEM 照片。结果显示, 其除铝的速度比 $5 \mathrm{wt} \%$ 的氢氧化钠溶液稍快, 与能谱扫描结果一致。 如图 4(d) (f)所示, 反应 $18 \mathrm{~min}$ 后铝电极完全被去 除, 由图 4(f)可见, 反应 $24 \mathrm{~min}$ 后也出现硅晶片与 溶液反应留下的凹槽。

图 5 为电池片与 $15 \mathrm{wt} \%$ 氢氧化钠溶液反应不同 时间的 SEM 照片。如图 5(c)所示, 表面铝电极已经 完全被去除, 与能谱检测结果一致。图 5(d) (f)中可 以看到明显的凹槽, 比在低浓度的氢氧化钠溶液中 形成的凹槽更深，表明硅晶片的腐蚀现象较为严重。

综上所述, 当氢氧化钠溶液浓度增大时, 其去 除铝电极的速度随之加快。完全去除铝电极之后延 长反应时间, 氢氧化钠溶液均会对硅晶片造成腐蚀, 且氢氧化钠浓度越高, 其腐蚀硅晶片的速度越快, 硅晶片表面的凹槽也越深。为了在实现高效率去除铝 电极的同时控制硅晶片的损失，确定在 $10 \mathrm{wt} \%$ 氢氧 化钠溶液中反应 $18 \mathrm{~min}$ 为去除铝背电极的最佳条件。

\section{2 银正电极的去除}

去除银电极结果如图 6 所示。

由图 6 可知, 太阳能电池片正面银的原子百分 比约为 $12.17 \%$, 分别进行化学溶解、超声清洗后其 原子百分比分别下降到 $0.31 \% 、 0.25 \%$ 。两种方法的 除银效果相当，几乎将银完全去除，而直接利用超 声清洗来回收银电极不会产生化学废液, 更符合经 济环境效益。且利用超声清洗之后获得的银电极仍 然是固态的银电极, 可以直接回收, 不需要后续处 理, 所以选用超声清洗为去除银正电极的最佳方法。

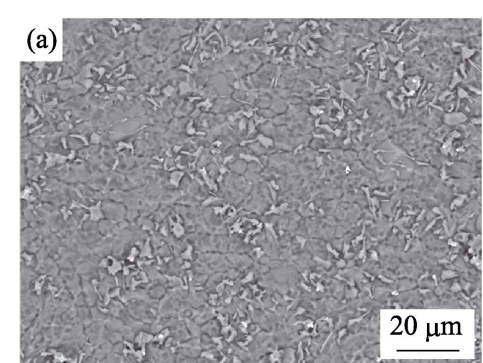

(d)

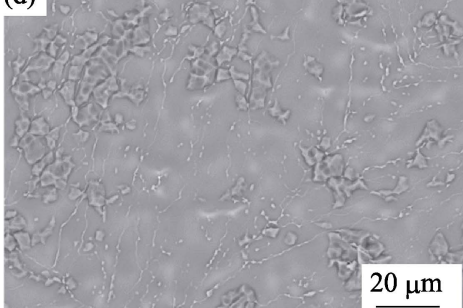

(b)

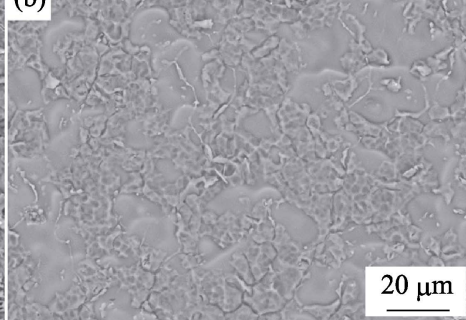

(e)

$20 \mu \mathrm{m}$ (f)

(c)

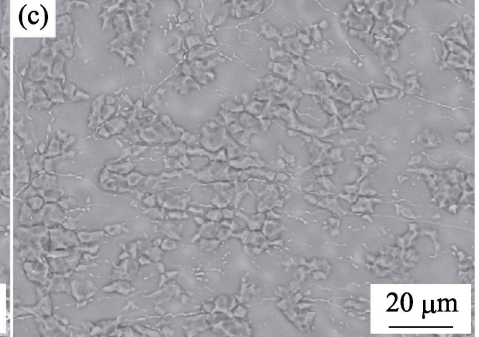

图 3 电池片与 $5 \mathrm{wt} \%$ 氢氧化钠溶液分别反应 9 (a)、12 (b)、15 (c)、18 (d)、21 (e) 和 24 min (f)之后背面铝电极的 SEM 照片

Fig. 3 SEM images of rear faces of multicrystalline cells after etching in $5 \mathrm{wt} \% \mathrm{NaOH}$ solution with 9 min (a), $12 \min (\mathrm{b}), 15 \min (\mathrm{c}), 8 \mathrm{~min}(\mathrm{~d}), 21 \mathrm{~min}(\mathrm{e})$ and $24 \min (\mathrm{f})$ 

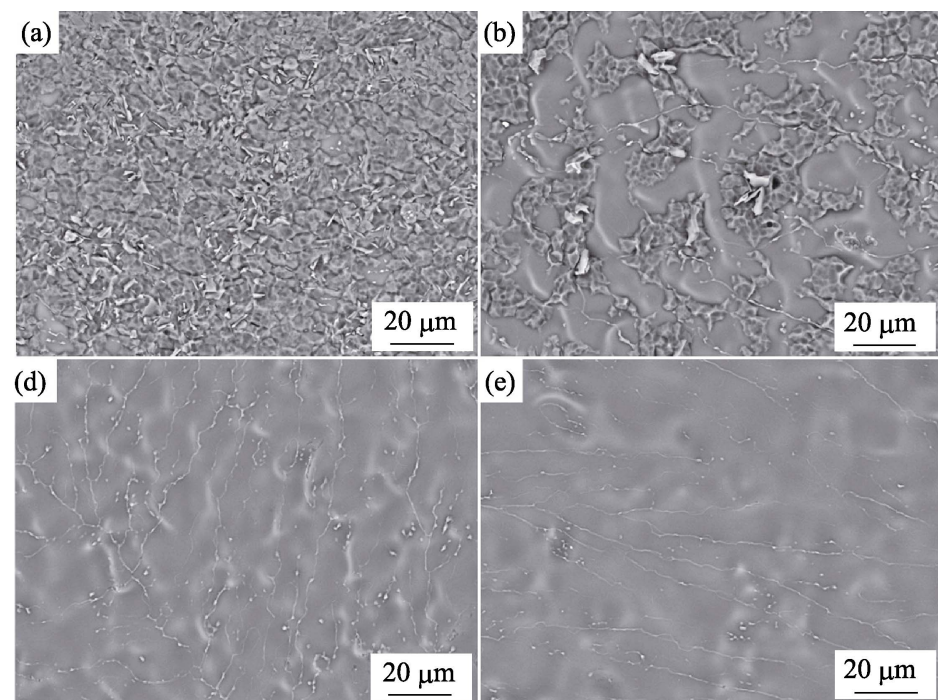

(e)

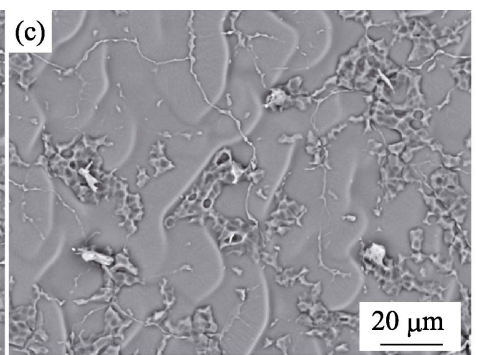

(f)

$20 \mu \mathrm{m}$

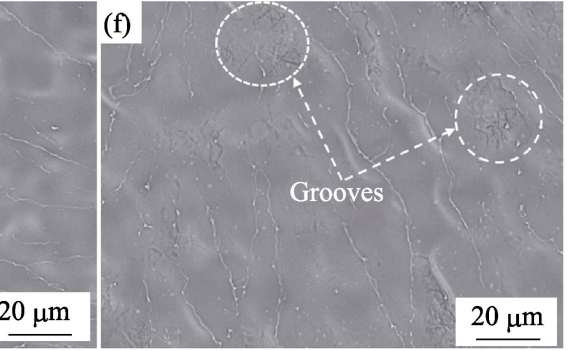

图 4 电池片与 $10 \%$ 氢氧化钠溶液分别反应 9(a)、12(b)、15(c)、18(d)、21(e) 和 $24 \min (\mathrm{f})$ 之后背面铝电极的 SEM 照片 Fig. 4 SEM images of rear faces of multicrystalline cells after etching in $10 \% \mathrm{NaOH}$ solution with 9 min (a), $12 \min (b), 15 \min (c), 18 \min (d), 21 \min (e)$ and $24 \min (f)$
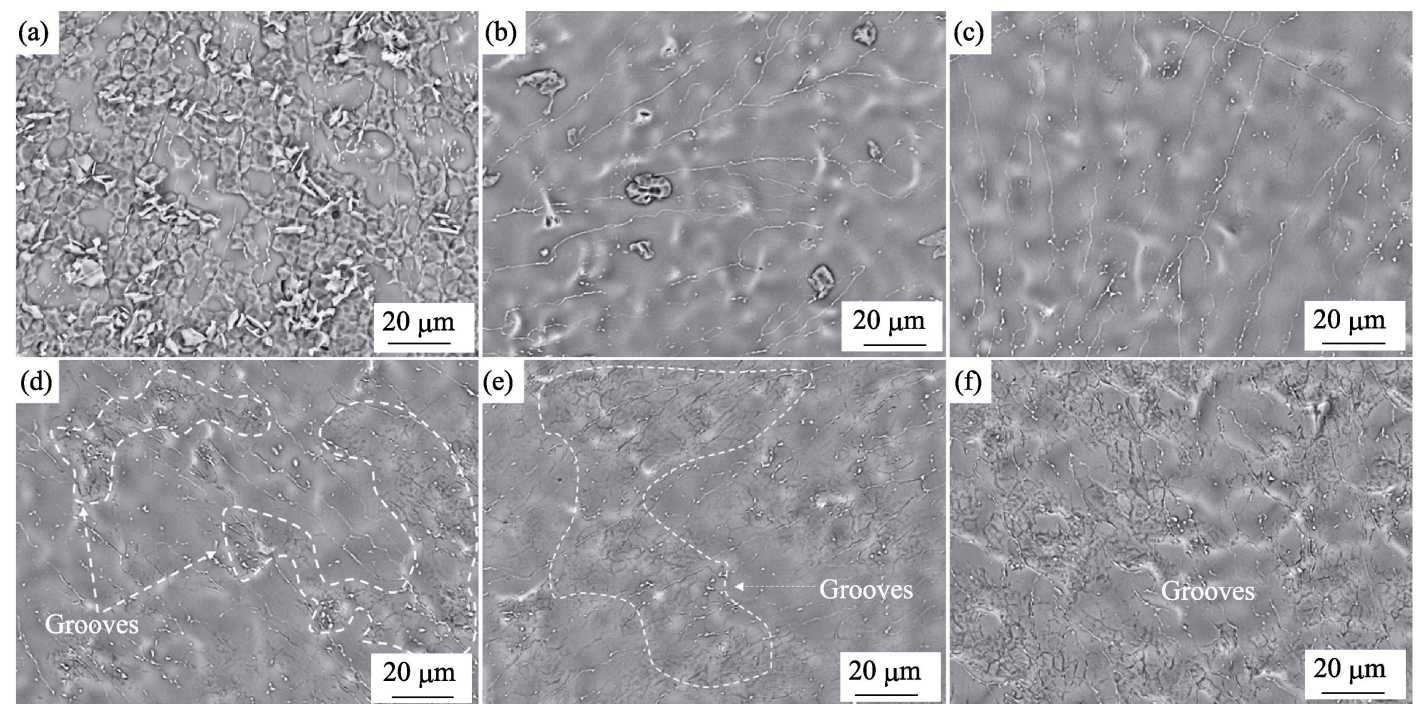

图 5 电池片与 $15 \%$ 氢氧化钠溶液分别反应 9(a)、12(b)、15(c)、18(d)、21(e)和 24 min(f)之后背面铝电极的 SEM 照片 Fig. 5 SEM images of rear faces of multicrystalline cells after etching in $15 \% \mathrm{NaOH}$ solution with 9 min (a), $12 \min (\mathrm{b}), 15 \min (\mathrm{c}), 18 \min (\mathrm{d}), 21 \min (\mathrm{e})$ and $24 \min (\mathrm{f})$

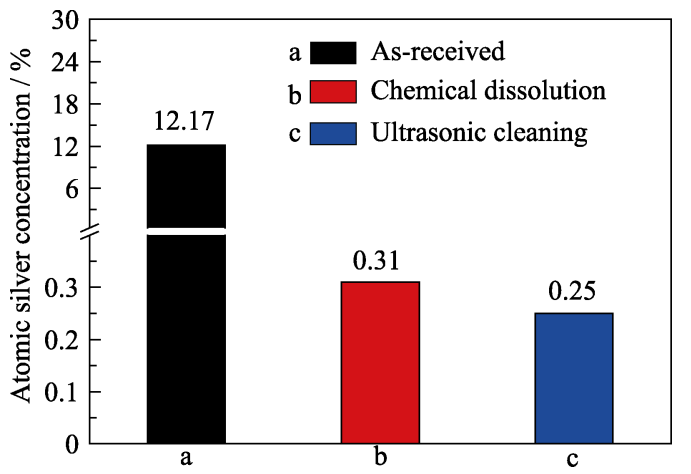

图 6 不同条件除银电极前后正面银原子 EDS 含量分析

Fig. 6 EDS analysis of front faces of multicrystalline cells before and after removing the $\mathrm{Ag}$ electrodes with different treatments
将已去除铝电极的电池片浸入去离子水中, 置 于超声清洗机中清洗, 电池片正面的银电极会自动 剥落, 随着时间的延长剥落的量逐渐增加, 而将未 与氢氧化钠反应的电池片放入超声清洗机中清洗, 则不会出现银电极剥落现象, 如图 7(a)是经过超声 清洗 $10 \mathrm{~min}$ 后已经部分剥落的银电极。将超声清洗 的时间延长至 15 20 min, 所有的银电极完全剥落, 部分呈条状, 部分呈碎屑状。这些剥落的银电极过 滤后可直接回收。

图 7(b)为剥落的银电极正面的 SEM 照片, 图 7(c) 为剥落的银电极反面, 即与氮化硅膜接触一侧的 SEM 照片，可观察到均匀的孔洞。 


\section{3 氮化硅减反射膜的去除}

对去除氮化硅膜实验前后的电池片正面 XPS 能 谱扫描结果用 XPS peakfit 4.1 软件进行拟合, 结果 如图 8。

图 8(a)所示为实验前的拟合结果, 1 处电子结合 能为 $102.510 \mathrm{eV}$, 查阅 XPS 电子结合能对照表可知 氮化硅键的电子结合能为 $102.000 \mathrm{eV}$ ，二者一致。 图 8(b)所示为去除氮化硅之后的拟合结果，显示 2、 3、4 处的电子结合能分别为 $103.040 、 99.460$ 和 $99.960 \mathrm{eV}$ 。查表可知, 2 处结合键为氮化硅键, 3、4 处为硅-硅-键 ${ }^{[18-20]}$ 。表明: 实验前电池片表面的成 分为氮化硅, 实验后为氮化硅和硅。XPS 结果显示 去除氮化硅膜之后氮的原子百分比从 $45.63 \%$ 下降 到 3.55\%，基本去除氮化硅。

\section{4 定量分析}

实验结果如表 1 。

单片多晶硅电池片的质量为 $8.9068 \mathrm{~g}$, 图 9 为 其宏观形貌图, 图 9 (a)为正面氮化硅减反射膜和银 电极, 图 9 (b)为背面铝电极。在最佳实验条件下去 除铝背电极和氮化硅减反射膜, 并通过超声清洗使 银电极剥落。通过实验除去 $1.1102 \mathrm{~g}$ 铝电极, 回收 得到 $0.0766 \mathrm{~g}$ 银电极和 $7.7169 \mathrm{~g}$ 硅晶片, 如图 10 所 示, 分别为最终回收得到的硅晶片(a)和银电极(b)的 宏观形貌图。

\section{3 结论}

本研究通过依次去除铝背电极、银正电极及氮 化硅减反射膜三个步骤回收硅晶片, 得出以下实验 结论:

1)采用氢氧化钠溶液去除铝电极, 最佳实验条 件为: 与 $10 \mathrm{wt} \%$ 氢氧化钠溶液反应 $18 \mathrm{~min}$ 。此反应 条件既实现了铝电极的高效率去除，同时硅晶片的 损失也较小。若溶液浓度高于 $10 \mathrm{wt} \%$ 将会加速硅晶片 的腐蚀, 浓度低于 $10 \mathrm{wt} \%$ 则会延长铝电极完全去除 的时间;

2)采用超声清洗去除银电极，将与氢氧化钠反 应后的电池片用去离子水超声 $(40 \mathrm{kHz}$ )清洗 $20 \mathrm{~min}$, 电池片表面银电极完全剥落, 除银效果清洁高效, 银电极易回收;

3)采用 $40 \mathrm{wt} \%$ 氢氟酸溶液去除氮化硅减反射膜, 反应 $10 \mathrm{~min}$ 后, XPS 结果显示氮化硅减反射膜被有 效去除;

4)本研究对单片太阳能电池片进行了定量实验: 单片多晶硅电池片质量为 $8.9068 \mathrm{~g}$, 在最佳实验条 件下去除 $1.1102 \mathrm{~g}$ 铝电极和氮化硅膜, 并通过超声 清洗获得 $0.0766 \mathrm{~g}$ 固态银电极之后, 回收得到 $7.7169 \mathrm{~g}$ 硅晶片。
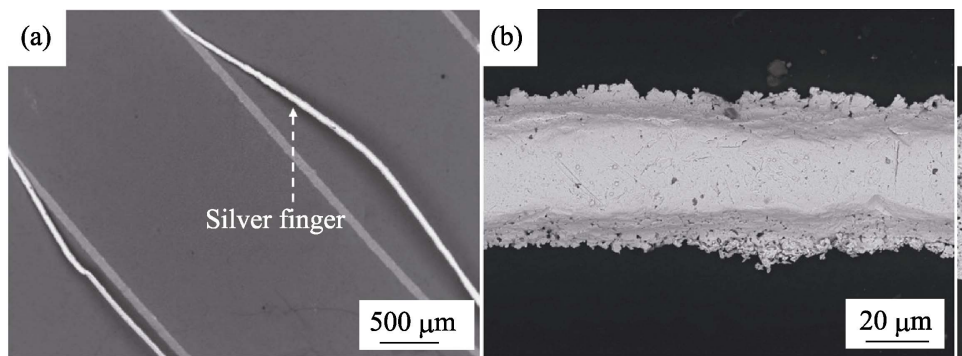

(c)

图 7 电池片除铝之后超声清洗部分剥落的银电极(a)和剥落的银电极正(b)反面(c)SEM 照片

Fig. 7 SEM images of front face with visible finger (a), front (b) and rear (c) faces of silver finger after ultrasonic cleaning
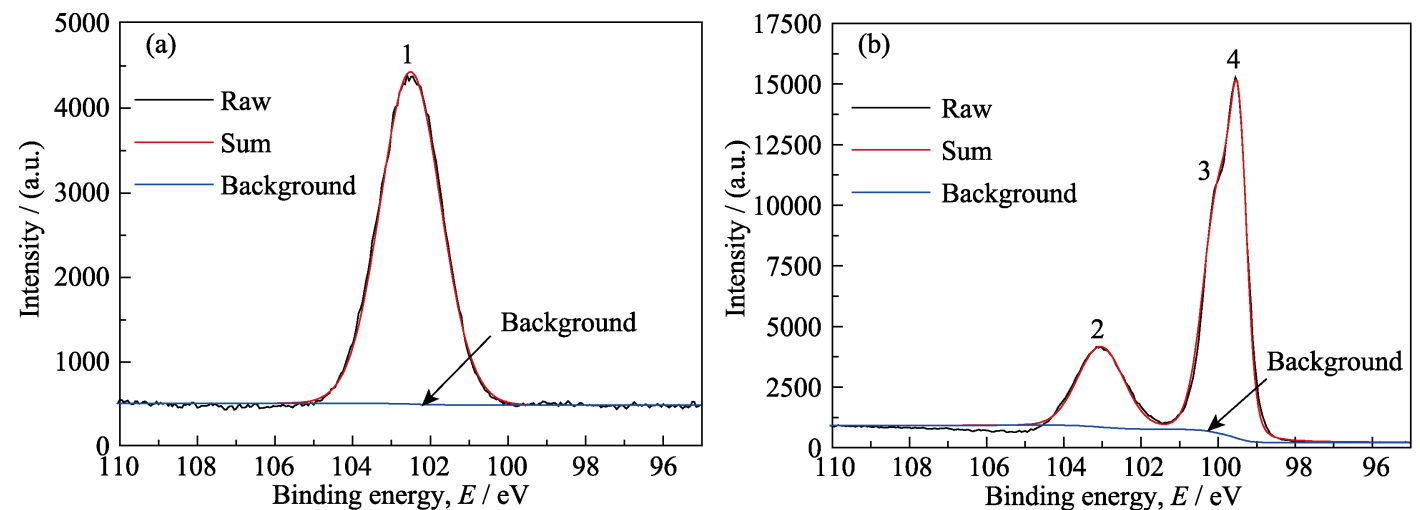

图 8 去除氮化硅膜前(a)后(b)电池片正面的 XPS 谱图拟合效果

Fig. 8 XPS analysis of front faces of multicrystalline cells before (a) and after (b) etching 
表 1 单片电池片各成分的质量

Table 1 The mass of each component of a multicrystalline cell

\begin{tabular}{ccccc}
\hline Component & Solar cell & Si wafer & Al electrode Ag electrode \\
\hline Mass $/ g$ & 8.9068 & 7.7169 & 1.1102 & 0.0766 \\
\hline
\end{tabular}

\section{(a)}
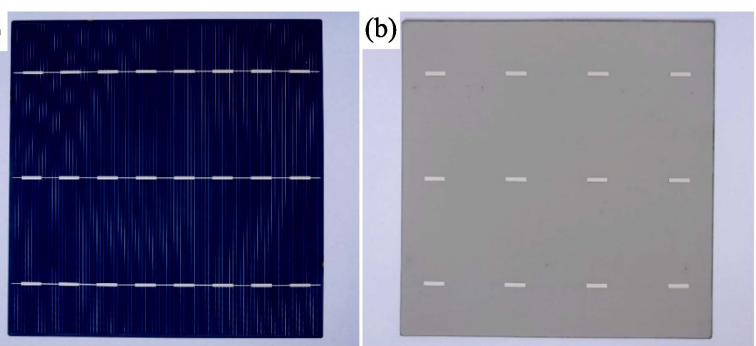

图 9 太阳能电池片的正(a)反(b)面宏观形貌图

Fig. 9 Views of a multicrystalline solar cell recovered from damaged cells: front (a) and rear (b) side
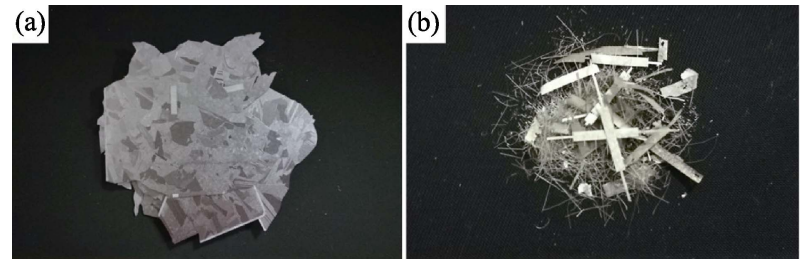

图 10 回收的硅晶片(a)、银电极(b)宏观形貌图

Fig. 10 Views of silicon wafers (a) and silver fingers (b) recovered from a multicrystalline solar cell

\section{参考文献:}

[1] YAN YUN-FEI, ZHANG ZHI-EN, ZHANG LI, et al. Application and utilization technology of solar energy. Acta Energiae Solaris Sinica, 2012, 33(sl): 47-56.

[2] PARK JONGSUNG, PARK NOCHANG. Wet etching processes for recycling crystalline silicon solar cells from end-of-life photovoltaic modules. RSC Advances, 2014, 4: 34823-34829.

[3] EWA KLUGMANN-RADZIEMSKA, PIOTR OSTROWSKI, KAZIMERZ DRABCZYK, et al. Experiment validation of crystalline silicon solar cells recycling by thermal and chemical methods. Solar Energy Material and Solar Cells, 2012, 94(12): 2275-2282.

[4] MCDONALD N C, PEARCE J M. Producer responsibility and recycling solar photovoltaic modules. Energy Policy, 2010, 38(11): 7041-7047.

[5] VASILIS M, FTHENAKIS. End-of-life management and recycling of PV modules. Energy Policy, 2000, 28(14): 1051-1058.
[6] 吴 昊. 高效多晶硅太阳能电池制备工艺研究. 长沙: 湖南大学 硕士学位论文, 2014.

[7] FU MING, ZHOU HONG, HUA KAI-WEI, et al. Aging characteristics of crystalline silicon solar cells. Electronic Components and Materials, 2017, 36(12): 79-83.

[8] HUANG WEN-HIS, TAO MENG. A Simple Green Process to Recycle Si from Crystalline-Si Solar Cells. Photovoltaic Specialist Conference, 2015IEEE 42nd, IEEE, 2015: 1-4.

[9] ZHANG LINGEN, XU ZHENMING. Separating and recycling plastic, glass, and gallium from waste solar cell modules by nitrogen pyrolysis and vacuum decomposition. Environmental Science and Technology, 2016, 50: 9242-9250.

[10] SONG ER-XIAO, ZHANG CHENG-LONG, MA EN, et al. Recovery processing status of waste crystalline silicon solar cell. Journal of Shanghai Polytechnic University, 2017, 34(3): 157-162.

[11] 董 莉. 废晶体硅太阳能电池板资源化技术研究. 成都: 西南交 通大学硕士学位论文, 2014

[12] LUO FU-XIANG, PENG XIAO-CHUN, WU YAN-YU, et al. Research progress of waste crystalline solar cells recycling and dismantling. Environmental Science and Management, 2014, 39(12): 160-163.

[13] EWA KLUGMANN-RADZIEMSKA, PIOTR OSTROWSKI. Chemical treatment of crystalline silicon solar cells as a method of recovering pure silicon from photovoltaic modules. Renewable Energy, 2010, 35(8): 1751-1759.

[14] BOMBACH E, ROVER I, MULLER A, et al. Technical Experience during Thermal Chemical Recycling of a 23 Year Old PV Generator Formerly Installed on Pellworm Island. 21st European Photovoltaic Solar Energy Conference, 2006: 2048-2053.

[15] LIU QING, REN MING-SHU, LIU ZI-YING. Study and market of front-side silver paste for silicon solar cell. Information Recording Materials, 2012, 13(2): 39-46.

[16] ZHANG LIFENG, CIFTJA ARIAN. Recycling of solar cell silicon scraps through filtration, Part I: Experimental investigation. Solar Energy Materials and Solar Cells, 2008, 92(11): 1450-1461.

[17] MA LING-LING, QIN ZHI-HONG, ZHANG LU, et al. Peak fitting methods and parameter setting in XPS analysis for organic sulfur in coal. Journal of Fuel Chemistry Technology, 2014, 42(3): 277-283.

[18] YIN ZONG-JIE, WANG TING, XING HUA-CHAO. Technique of data processing method during XPS analysis. Shandong Chemical Industry, 2017, 46(12): 89-93.

[19] LIU FEN, ZHAO ZHI-JUAN, QIU LI-MEI, et al. Tables of peak positions for XPS photoelectron and auger electron peaks. Analysis and Testing Technology and Instruments, 2009, 15(1): 1-17.

[20] TORU YAMASHITA, PETER HAYES. Analysis of XPS spectra of $\mathrm{Fe}^{2+}$ and $\mathrm{Fe}^{3+}$ ions in oxide materials. Applied Surface Science, 2008, 254(8): 2441-2449. 